\title{
Color, phenolic and flavonoid content, and antioxidant activity of honey from Roraima, Brazil
}

Jonierison Alves PONTIS ${ }^{1,2}$, Luiz Antonio Mendonça Alves da COSTA ${ }^{1}$, Silvio José Reis da SILVA³, Adriana FLACH ${ }^{1 *}$

\begin{abstract}
The total phenolic and flavonoid content, color, and antioxidant activity were evaluated from ten honey samples from Apis mellifera L. collected from Roraima State, Brazil. The total phenolic content was determined using the Folin-Ciocalteu reagent and ranged from 250 to $548 \mathrm{mg}$ gallic acid $\mathrm{kg}^{-1}$ of honey. The total flavonoid content was obtained using two methods: total flavones/flavonols were determined with aluminum chloride, and flavonones/dihydroflavonols were determined with 2,4-dinitrophenylhydrazine.

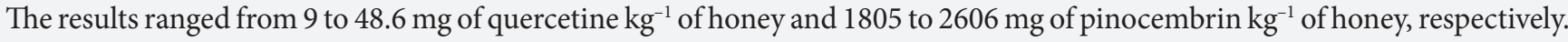
Antioxidant activity was measured with 2,2-diphenyl-1-picrylhydrazyl (DPPH) radical scavengers, and the results of the IC ranged from 3.17 to $8.79 \mathrm{mg} / \mathrm{mL}$. Statistical analysis demonstrated positive correlations between color intensity, flavone and flavonol content, and phenolic content and negative correlations with antioxidant capacity.
\end{abstract}

Keywords: Folin-Ciocalteu; 2,4-dinitrophenylhydrazine; 2,2-diphenyl-1-picrylhydrazyl.

\section{Introduction}

Honey has been used by humanity for thousands of years for nutrition and curative purposes. It is an aqueous solution of sugars containing a few secondary metabolites. Several studies have shown that the variability in sugars and secondary metabolites are related to the source and botanical origin of the nectar. Honey is recognized as having different biological properties, including antioxidant effects. Phenolic acids and flavonoids are the main antioxidants in this apiary product (Bertoncelj et al., 2007; Socha et al., 2009). Several studies have been conducted to determine the antioxidant activity and phenolic content in honey. Kishore et al. (2011) studied phenolic content of honey using the Folin-Ciocalteu method. Data on the antioxidant activity of honey from Malaysia suggest that the phenolics are responsible for free-radical scavenging and antioxidant activity. Another important class of compounds in products derived from bees are flavonoids (Chang et al., 2002; Popova et al., 2004, 2007; Lebranc et al., 2009; Tylkowski et al., 2010). The total flavonoid content is generally determined using a spectrophotometric assay based on the formation of an aluminum chloride complex, which has been applied for quantification of flavones and flavonols in honey (Meda et al., 2005; Liberato et al., 2011). Although the flavonone and dihydroflavonol content has not yet been determined in honey, these compounds have largely been determined in propolis and pollen using the 2,4-dinitrophenylhydrazine method (Chang et al., 2002; Popova et al., 2004, 2007; Lebranc et al., 2009; Tylkowski et al., 2010). An important parameter of honey is its color, which reflects the floral source (Bertoncelj et al., 2007) and can be determined by spectrophotometric measurement of the absorbance of a 50\% honey solution at 635 $\mathrm{nm}$ and classified according to the Pfund scale (Ferreira et al., 2009; Lacerda et al., 2010). Statistical analysis of the phenolic content, color, and antioxidant activity has demonstrated positive correlations (Bertoncelj et al., 2007). Beretta et al. (2005) studied fourteen commercial honey samples from different floral and geographic origins and determined the phenolic content using spectrophotometric assay and the Folin-Ciocalteu reagent. Antioxidant activity was assessed with the ferric reducing ability of plasma (FRAP) and DPPH assays, and antilipoperoxidant activity was determined using ORAC and color intensity $\left(\mathrm{ABS}_{450}\right)$. All data were correlated using the principal component analysis (PCA), and significant correlations were obtained between antioxidant activity, phenolic content, and color intensity.

The aim of this study was to quantitatively analyze the phenolic and flavonoid contents, color intensity, and antioxidant properties of honey samples collected from different regions in the state of Roraima, Brazil, and to describe the relationship between these samples using Pearson's correlation.

\section{Materials and methods}

\subsection{Samples}

Ten multifloral honey samples from Apis mellifera were obtained directly from beekeepers in 2009 and 2010 from different locations and vegetation sources in Roraima, Brazil (Table 1).

\footnotetext{
Received 25 July, 2013

Accepted 31 Jan., 2014 (006158)

${ }^{1}$ Departamento de Química, Universidade Federal de Roraima - UFRR, Campus Paricarana, Boa Vista, RR, Brasil, e-mail: aflach@gmail.com

2 Instituto Federal de Educação, Ciência e Tecnologia de Roraima - IFRR, Campus Amajari, Amajari, RR, Brasil

3 Universidade Estadual de Roraima - UERR, Boa Vista, RR, Brasil

${ }^{*}$ Corresponding author
} 
Table 1. Distribution of honey samples.

\begin{tabular}{cccc}
\hline Sample & City & State & Characteristic vegetation \\
\hline MJP1 & Amajari & Roraima & Savanna \\
MJP2 & Amajari & Roraima & Savanna \\
MJP3 & Mucajai & Roraima & Amazon forest \\
MJP4 & Mucajai & Roraima & Amazon forest \\
MJP5 & Cantá & Roraima & Savanna \\
MJP6 & Cantá & Roraima & Savanna \\
MJP7 & Cantá & Roraima & Savanna \\
MJP8 & Cantá & Roraima & Savanna \\
MJP9 & Cantá & Roraima & Savanna \\
MJP10 & São Luiz do Anauá & Roraima & Amazon forest \\
\hline
\end{tabular}

\subsection{Color intensity: $A B S_{635 \mathrm{~nm}}$}

Honey was diluted to $50 \%(\mathrm{w} / \mathrm{v})$ with distilled water, homogenized, and centrifuged at $3200 \mathrm{rpm}$ for five minutes. Absorbance was determined at $635 \mathrm{~nm}$ using a spectrophotometer, and color intensity was determined using the Pfund scale (Ferreira et al., 2009; Lacerda et al., 2010).

\subsection{Determination of total phenolic content}

The total phenolic content was determined using the FolinCiocalteu method, and the results were expressed as mg gallic $\mathrm{acid} / \mathrm{kg}$ honey. Initially, honey solutions were prepared at a concentration of $0.1 \mathrm{~g} / \mathrm{mL}$. An aliquot of $0.5 \mathrm{~mL}$ of the stock solution was mixed with $0.3 \mathrm{~mL}$ of the Folin-Ciocalteu reagent and $2 \mathrm{~mL}$ of a $15 \%$ sodium carbonate solution. Distilled water was added to a final volume of $5 \mathrm{~mL}$. Following incubation for $2 \mathrm{~h}$, the absorbance of the reaction mixture was measured at $798 \mathrm{~nm}$ against a blank of distilled water. A standard curve of gallic acid was drawn within a concentration range of $7.0 \times 10^{-4}$ to $7.8 \times 10^{-3} \mathrm{mg} / \mathrm{mL}$ (Socha et al., 2007; Ferreira et al., 2009).

\subsection{Determination of flavones and flavonols}

The total flavone and flavonol contents of the honey samples were determined using aluminum chloride, and the results were expressed as mg quercetin/kg honey. The honey solutions were prepared at the concentration of $0.2 \mathrm{~g} / \mathrm{mL}$. Two milliliters $(2 \mathrm{~mL})$ of the stock solution were mixed with $3 \mathrm{~mL}$ of a $5 \%$ aluminum chloride solution. Following incubation for $30 \mathrm{~min}$, the absorbance of the reaction mixture was measured at 437 nm against a methanol blank. A standard curve of quercetin was drawn within a concentration range of $3.0 \times 10^{-4}$ to $4.0 \mathrm{x}$ $10^{-3} \mathrm{mg} / \mathrm{mL}$ (Chang et al., 2002; Popova et al., 2005, 2007; Tylkowski et al., 2010; Gómez-Caravaca et al., 2006).

\subsection{Determination of flavonones and dihydroflavonols}

The flavonone and dihydroflavonol contents of the honey samples were determined using dinitrophenylhydrazine, and the results were expressed as $\mathrm{mg}$ pinocembrin/kg honey. A $0.2 \mathrm{~mL}$ aliquot of the stock solution $(0.2 \mathrm{~g} / \mathrm{mL})$ and $0.4 \mathrm{~mL}$ of a 2,4-dinitrophenylhydrazine (DNP) solution ( $0.5 \mathrm{~g}$ DNP in $1 \mathrm{~mL} 96 \%$ sulfuric acid diluted to $50 \mathrm{~mL}$ with methanol in a volumetric flask) were heated to $50{ }^{\circ} \mathrm{C}$ for $50 \mathrm{~min}$ in a water bath. After cooling to room temperature, the mixture was diluted to a total of $1.4 \mathrm{~mL}$ with $10 \% \mathrm{KOH}$ in methanol/water (7:3). A $0.15 \mathrm{~mL}$ aliquot of the resulting solution was diluted to $5 \mathrm{~mL}$ with methanol and centrifuged at $2800 \mathrm{rpm}$ for five minutes. The absorbance of the supernatant solution was measured at 486 $\mathrm{nm}$ against a methanol blank. A standard curve of pinocembrin was drawn within a concentration range of $5.0 \times 10^{-4}$ to $4.0 \mathrm{x}$ $10^{-3} \mathrm{mg} / \mathrm{mL}$ (Chang et al., 2002; Popova et al., 2004, 2007; Tylkowski et al., 2010; Gómez-Caravaca et al., 2006).

\subsection{Antiradical activity: $\mathrm{DPPH}^{\cdot}$ assay}

The antiradical activity of the honey samples was estimated using the 2,2-diphenyl-1-picrylhydrazyl hydrate radical $\left(\mathrm{DPPH}^{\circ}\right)$. The honey samples were dissolved in distilled water at concentrations ranging from 1.74 to $12.60 \mathrm{mg} / \mathrm{mL}$, and $3.5 \mathrm{~mL}$ of each solution was mixed with $1.5 \mathrm{~mL}$ of DPPH ${ }^{\text {. }}$ $(0.1 \mathrm{mM})$. After the mixtures were shaken and left for 30 min at room temperature in the dark, the absorbance of the remaining $\mathrm{DPPH}^{\circ}$ was measured at $515 \mathrm{~nm}$ and converted into the percentage of antioxidant activity (AA) using the following formula:

$$
\mathrm{AA} \%=100-\left\{\left[\left(\mathrm{Abs}_{\text {sample }_{\text {e }}}-\mathrm{Abs}_{\text {blank }}\right) \times 100\right] / \mathrm{Abs}_{\text {control }}\right\}
$$

The blank consisted of a honey solution $(1.5 \mathrm{~mL})$ at the same concentration values previously described and $3.5 \mathrm{~mL}$ of methanol. The negative control consisted of $3.5 \mathrm{~mL}$ of methanol with $1.5 \mathrm{~mL}$ of the $\mathrm{DPPH}^{*}$ solution. The positive controls consisted of standard solutions of gallic acid and quercetin. The $\mathrm{IC}_{50}$ values were calculated using linear regression of plots where the abscissa represented the concentration of the honey solution and the ordinate was the percent of antioxidant activity (Bertoncelj et al., 2007; Socha et al., 2009; Ferreira et al., 2009; Mesor et al., 2001; Baltrušaitytė et al., 2007).

\subsection{Statistical analysis}

All analyses were carried out in triplicate, and the data were expressed as mean \pm standard deviation (SD). Analysis of variance (ANOVA) was used to test for statistical significance difference between phenolic and flavonoid contents. Differences at a $95 \%(p<0.05)$ confidence level were considered statistically significant. Correlations between the parameters evaluated were obtained using Pearson's correlation coefficient $(r)$.

\section{Results and discussion}

There are a number of published studies regarding correlations between the various parameters of honey including color, antioxidant activity, and phenolic and flavonoid contents (Bertoncelj et al., 2007; Socha et al., 2009; Ferreira et al., 2009; Beretta et al., 2005; Kaškonienè et al., 2009). Bertoncelj et al. (2007) studied unifloral and multifloral honeys from Slovenia and found statistical correlations between these parameters. Using unifloral honeys from the northeastern region in Portugal, Ferreira et al. (2009) showed that dark honeys were richer in phenolics and had a higher antioxidant activity. Beretta et al. 
(2005) demonstrated a positive relationship between phenolic concentration, antioxidant capacity and the color of unifloral and multifloral honeys. Darker honeys tend to have higher antioxidant activity and an increased concentration of phenolic compounds (Kaškonienè et al., 2009).

\subsection{Color intensity: $A B S_{635 n m}$}

While collecting honey samples, it was observed an obvious difference in their color intensity. In order to classify the honey samples according to color, a method that is easily implemented was used. Honey can be classified as water white, extra white, white, extra light amber, light amber, amber, and dark amber. No honey samples in the present study were water white, extra white, and amber. The predominant color of the honey samples studied was dark amber (40\%). Light amber and extra light amber accounted for $20 \%$ and $30 \%$, respectively, and white represented $10 \%$ of the total samples evaluated. Honey from the same origin can have different color intensities, for example, MJP1 was dark amber and MJP2 was white (Table 2).

\subsection{Determination of total phenolic content}

A colorimetric assay using the Folin-Ciocalteu reagent is often referenced in the literature for the determination of phenolic compounds (Bertoncelj et al., 2007; Socha et al., 2009; Ferreira et al., 2009; Beretta et al., 2005; Kaškonienè et al., 2009). The reaction between the Folin-Ciocalteu reagent and phenolic compounds results in the formation of a blue color complex that absorbs radiation and allows quantification. The total phenol content (mg gallic acid $\mathrm{kg}^{-1}$ of honey) of the different honey samples was investigated using a modified Folin-Ciocalteau assay. The phenolic concentration of honey in this study ranged from 250 to $509 \mathrm{mg}$ of gallic acid $\mathrm{kg}^{-1}$ of honey (Table 2). The honey sample with the highest phenolic content was the MJP10, from the Amazon forest, and the sample with the lowest content was the MJP2, from a mountain savanna area (Table 2). Evaluating honey from the northeast of Portugal, Ferreira and others (Ferreira et al., 2009) reported phenol contents ranging from 226.16 to $727.77 \mathrm{mg}$ of gallic acid $\mathrm{kg}^{-1}$ of honey. Beretta et al. (2005) reported contents ranging from 52.2 to $789.6 \mathrm{mg} \mathrm{kg}^{-1}$ for unifloral and multifloral honeys from Africa. In a study on Slovenian honey, Bertoncelj et al.
(2007) obtained results that ranged from 44.8 to $233.9 \mathrm{mg} \mathrm{kg}$. Honey samples from northeastern region in Brazil had phenol contents ranging from 102.1 to $1085 \mathrm{mg}$ gallic acid kg-1 of honey (Liberato et al., 2011). The results obtained in the present study showed less variation than that found by those authors, and the values are within the range obtained by other authors that evaluated multifloral honey samples.

\subsection{Determination of flavonoids}

The flavonoid content was obtained using two methods. The first method uses aluminum chloride and is based on the formation of a complex between the aluminum ion, $\mathrm{Al}$ (III), and the carbonyl and hydroxyl groups of flavones and flavonols that produce a yellow color (Popova et al., 2004). In this study, the total flavone and flavonol content ranged from 9.0 to $48.6 \mathrm{mg}$ of quercetin $\mathrm{kg}^{-1}$ of honey (Table 2). The honey sample MJP4, from the Amazon forest, had the highest flavone and flavonol content $\left(48.6 \mathrm{mg} \mathrm{kg}^{-1}\right)$, and the sample MJP3, from the Amazon forest ( $9.0 \mathrm{mg} \mathrm{kg}^{-1}$ ), had the lowest content. Meda et al. (2005) evaluated twenty-seven Burkina Fasan honey samples and determined their flavonoid content using the aluminum chloride method, and their results ranged from 17 to $83.5 \mathrm{mg}$ of quercetin $\mathrm{kg}^{-1}$ of honey. The flavonoid results in this study were lower than the results obtained for honey from the northeast of Brazil, which ranged from 2.5 to $83.8 \mathrm{mg}$ of quercetin $\mathrm{kg}^{-1}$ of honey (Liberato et al., 2011).

The colorimetric method with DNP (2,4-dinitrophenylhydrazine) is commonly used to evaluate propolis samples (Chang et al., 2002; Popova et al., 2005, 2007; Tylkowski et al., 2010). The principle of this method is that the 2,4-dinitrophenylhydrazine reagent reacts with the carbonyl of ketones and aldehydes to form 2,4-dinitrophenylhydrazone, resulting in a red color (Chang et al., 2002). The total flavonone and dihydroflavonol content in this study ranged from 1706 to $2606 \mathrm{mg}$ of pinocembrin $\mathrm{kg}^{-1}$ of honey (Table 2). The honey sample with the highest flavonone and dihydroflavonol content was MJP1 (2606 $\mathrm{mg} \mathrm{kg}^{-1}$ ), from a mountain savanna.

The individual results of the two parameters used to determine the flavonoid content in the honey samples are shown in Table 2. The concentration of flavonones and dihydroflavonols was higher compared to that of flavones and flavonols. Popova

Table 2. Color intensity, phenolic content $(\mathrm{mg} / \mathrm{kg})$, flavonoid content $(\mathrm{mg} / \mathrm{kg})$, and $\mathrm{IC}_{50}$ values $(\mathrm{mg} / \mathrm{mL})$ obtained from the antioxidant activity of honey samples (mean $\pm \mathrm{SD} ; \mathrm{n}=3$ ).

\begin{tabular}{|c|c|c|c|c|c|c|}
\hline Sample & Color & Color (mm Pfund) & $\begin{array}{c}\text { Total phenolic } \\
\text { content }\end{array}$ & $\begin{array}{c}\text { Total flavones and } \\
\text { flavonols }\end{array}$ & $\begin{array}{c}\text { Total flavonones and } \\
\text { dihydroflavonols }\end{array}$ & $\begin{array}{c}\text { Radical-scavenging } \\
\text { activity }\left(\mathrm{IC}_{50}\right)\end{array}$ \\
\hline MJP1 & Dark amber & 156.28 & $444 \pm 6.36^{\mathrm{d}}$ & $42.5 \pm 2.48^{f}$ & $2606 \pm 76.8^{d}$ & 3.28 \\
\hline MJP2 & White & 31.12 & $250 \pm 3.24^{\mathrm{e}}$ & $15.2 \pm 0.25^{b}$ & $1866 \pm 57.7^{\mathrm{a}}$ & 4.55 \\
\hline MJP3 & Extra light amber & 35.58 & $269 \pm 3.08^{\mathrm{a}}$ & $9.0 \pm 0.07^{\mathrm{g}}$ & $1706 \pm 78.8^{\mathrm{a}}$ & 8.79 \\
\hline MJP4 & Dark amber & 166.68 & $509 \pm 7.04^{\mathrm{f}}$ & $48.6 \pm 0.2^{\mathrm{d}, \mathrm{e}}$ & $2050 \pm 0.0^{\mathrm{b}}$ & 3.20 \\
\hline MJP5 & Dark amber & 159.99 & $535 \pm 3.08^{g}$ & $47.1 \pm 0.45^{\mathrm{d}}$ & $1805 \pm 154.7^{\mathrm{a}}$ & 3.39 \\
\hline MJP6 & Light amber & 55.63 & $303 \pm 0.00^{c}$ & $17.8 \pm 0.93^{c}$ & $2139 \pm 19.0^{\mathrm{b}, \mathrm{c}}$ & 6.01 \\
\hline MJP7 & Extra light amber & 39.29 & $292 \pm 8.03^{b}$ & $17.5 \pm 0.75^{\mathrm{c}}$ & $2261 \pm 62.9^{c}$ & 6.20 \\
\hline MJP8 & Extra light amber & 42.26 & $274 \pm 1.22^{\mathrm{a}}$ & $14.2 \pm 0.93^{\mathrm{a}}$ & $2144 \pm 150.3^{\mathrm{b}, \mathrm{c}}$ & 6.70 \\
\hline MJP9 & Light amber & 71.23 & $305 \pm 8.63^{c}$ & $15.4 \pm 0.76^{\mathrm{a}, \mathrm{b}}$ & $2300 \pm 0.0^{c}$ & 4.15 \\
\hline MJP10 & Dark amber & 151.08 & $548 \pm 3.00^{\mathrm{h}}$ & $47.9 \pm 1.58^{\mathrm{d}, \mathrm{e}}$ & $2233 \pm 185.8^{c}$ & 3.17 \\
\hline
\end{tabular}


Table 3. Correlation matrix of the studied parameters (Pearson correlation coefficients).

\begin{tabular}{ccccc}
\hline & Color & Phenolics & Flavones and flavonols & $\begin{array}{c}\text { Flavonones and } \\
\text { dihydroflavonols }\end{array}$ \\
\hline Color & 1 & & & \\
Phenolics & 0.967 & 1 & & \\
IC & & \\
Flavones and flavonols & 0.924 & 0.926 & 1 & 1 \\
Flavonones and & 0.259 & -0.007 & 0.205 & -0.391 \\
dihydroflavonols & & -0.752 & -0.767 & 1 \\
IC $_{50}$ & -0.800 & & & \\
\hline
\end{tabular}

and others (Popova et al., 2004) stated the importance of using both methods (aluminum chloride and DNP) to determine flavonoid content in samples of poplar propolis because there are large quantities of flavonones in poplar propolis standards. Although it is a major honey constituent, flavonones were not used as a reference compound for determining the total flavonoid content in poplar propolis. As a result, the values of total flavonoid content were low (Popova et al., 2004). Other published studies on propolis and pollen show similar results (Chang et al., 2002; Popova et al., 2004; Lebranc et al., 2009; Tylkowski et al., 2010; Kosalec et al., 2004; Orsolić et al., 2007). There are no data on the quantification of dihydroflavonols and flavones in honey samples available in the literature for comparison.

\subsection{Antiradical activity: DPPH assay}

Among the several methods commonly used to investigate the antioxidant capacity of natural products, the free radical reagent 2,2-diphenyl-1-picryl-hydrazyl $\left(\mathrm{DPPH}^{\circ}\right)$ was chosen because it is an easy, precise, and accurate method (Alves et al., 2010). DPPH is a free radical, which is stable at room temperature and produces a violet solution in alcohol . It is reduced in the presence of an antioxidant molecule. The evaluation of the antioxidant activity of each honey sample was determined based on the scavenging activity against the free radical 2,2-diphenyl-1-picryl-hydrazyl (DPPH $\left.{ }^{\circ}\right)$ through the $\mathrm{IC}_{50}$ parameter, which represents the concentration of the material in question necessary to inhibit $50 \%$ of free radicals. Thus, a lower $\mathrm{IC}_{50}$ value in honey indicates a greater ability to neutralize free radicals. This method is commonly used to evaluate honey and propolis samples (Bertoncelj et al., 2007; Socha et al., 2009; Tylkowski et al., 2010; Ferreira et al., 2009; Mesor et al., 2001; Baltrušaityte et al., 2007). Table 2 shows the scavenging ability of multifloral honey samples expressed as $\mathrm{IC}_{50}$ with respect to the $\mathrm{DPPH}^{\circ}$ radical, which ranged from 3.17 to $8.79 \mathrm{mg} / \mathrm{mL}$. Sample MJP10, produced in the Amazon forest, had the highest antioxidant capacity $(3.17 \mathrm{mg} / \mathrm{mL})$. The results obtained by Bertoncelj et al. (2007) ranged from 7.2 to $53.8 \mathrm{mg} / \mathrm{mL}$. In a study conducted by Ferreira et al. (2009), the antioxidant values ranged from 106.67 to $168.94 \mathrm{mg} / \mathrm{mL}$, and according to data from Beretta et al. (2005), they ranged from 1.63 to $47.62 \mathrm{mg} / \mathrm{mL}$. Honey from the northeast of Brazil had $\mathrm{IC}_{50}$ values ranging from 4.2 to $106.72 \mathrm{mg} / \mathrm{mL}$ although most values were above $20 \mathrm{mg} / \mathrm{mL}$ (Liberato et al., 2011). These results showed that the honey samples collected in the present study have greater antioxidant potential compared to the results reported in the literature.

\subsection{Correlation between parameters}

A correlation matrix, presented in Table 3, was created to explore the possible relationships between the various parameters studied.

There was a positive correlation between color intensity, flavone and flavonol content, phenolic content, and antioxidant capacity. The darker honey samples had the highest antioxidant capacity and higher phenolic, flavone, and flavonol contents. The relationship between these parameters can be observed in samples MJP1, MJP4, MJP5, and MJP10 without the use of statistical analysis. The MJP4 honey sample showed higher color intensity and higher flavone and flavonol content. The MJP10 sampled showed higher antioxidant capacity and higher phenolic content. Color parameters and phenolic compounds were shown to have the highest correlation $(r=0.967)$. Flavonones and dihydroflavonols did not show any significant correlations with color parameters, flavone and flavonol content, phenolic content, and antioxidant capacity. Significant correlations between color parameters, phenolics, and antioxidant capacity have been demonstrated by Beretta et al. (2005), Ferreira et al. (2009) and Bertoncelj et al. (2007).

\section{Conclusions}

The present study established a correlation between the color, flavone, flavonol, and phenolic contents, and antioxidant capacity of the honey samples evaluated. Darker honey samples had higher amounts of phenolic compounds, flavones, and flavonols and increased antioxidant activity. Although the flavonone and dihydroflavonol content was observed to be high, no correlations between flavonones and dihydroflavonols were observed in this study. Based on the $\mathrm{IC}_{50}$ values, the honey samples from Roraima showed antioxidant potential. This is the first study to evaluate honey from Roraima. Future studies will identify and quantify individual flavonoids and phenolic acids of these honey samples.

\section{Acknowledgments}

The authors are grateful for the financial support provided by Conselho Nacional de Desenvolvimento Científico e Tecnológico - Brazil (Proc. 1474242/2008-0) and to Coordenação de Aperfeiçoamento de Pessoal de Nível Superior for granting a scholarship (Jonierison Alves Pontis). 


\section{References}

Alves, C. Q., David, J. M., David, J. P., Bahia, M. V., \& Aguiar, R. M. (2010). Métodos para determinação de atividade antioxidante in vitro em substratos orgânicos. Química Nova, 33(10), 2202-2210. http://dx.doi.org/10.1590/S0100-40422010001000033

Baltrušaitytė, V., Venskutonis, P. R., \& Čeksteryte, V. (2007). Radical scavenging activity of different floral origin honey and beebread phenolic extratcts. Food Chemistry, 101, 502-514. http://dx.doi. org/10.1016/j.foodchem.2006.02.007

Beretta, G., Granata, P., Ferrero, M., Orioli, M., \& Facino, R. M. (2005). Standardization of antioxidant properties of honey by a combination of spectrophotometric/fluorimetric assays and chemometrics. Analytica Chimica Acta, 533, 185-191. http://dx.doi.org/10.1016/j. aca.2004.11.010

Bertoncelj, J., Doberšek, U., Jamnik, M., \& Golob, T. (2007). Evaluation of the phenolic content, antioxidant activity and colour of Slovenian honey. Food Chemistry, 105, 822-828. http://dx.doi.org/10.1016/j. foodchem.2007.01.060

Chang, C. C., Yang, M. H., Wen, H. M., \& Chern, J. C. (2002). Estimation of total flavonoid content in propolis by two complementary colorimetric methods. Journal of Food and Drug Analysis, 10, 178-182.

Ferreira, I. C. F. R., Aires, E., Barreira, J. C. M., \& Estevinho, L. M. (2009). Antioxidant activity of Portuguese honey samples: Different contributions of the entire honey and phenolic extract. Food Chemistry, 114, 1438-1443. http://dx.doi.org/10.1016/j. foodchem.2008.11.028

Gómez-Caravaca, A. M., Gómez-Romero, M., Arráez-Romám, D., Segura-Carretero, A., \& Fernández-Gutiérrez, A. (2006). Advances in the analysis of phenolic compounds in products derived from bees. Journal of Pharmaceutical and Biomedical Analysis, 41, 12201234. PMid:16621403. http://dx.doi.org/10.1016/j.jpba.2006.03.002

Kaškonienė, V., Maruška, A., \& Kornyšova, O. (2009). Quantitative and qualitative determination of phenolic compounds in honey. Chemine Technologija, 52(3), 74-80.

Kishore, R. K., Halim, A. S., Syazana, M. S. N., \& Sirajudeen, K. S. N. (2011). Tualang honey has higher phenolic content and greater radical scavenging activity compared with other honey sources. Nutrition Research, 31, 322-325. PMid:21530807. http://dx.doi. org/10.1016/j.nutres.2011.03.001

Kosalec, I., Bakmaz, M., Pepeljnjak, S., \& Vladimir-Knežević, S. (2004). Quantitative analysis of the flavonoids in raw propolis from northern Croatia. Acta Pharmacy, 54, 65-72. PMid:15050046.

Lacerda, J. J. J., Santos, J. S., Santos, S. A., Rodrigues, G. B., \& Santos, M. L. P. (2010). Influência das características físico-químicas e composição elementar nas cores de méis produzidos por Apis mellifera no sudoeste da Bahia utilizando análise multivariada.
Química Nova, 33(5), 1022-1026. http://dx.doi.org/10.1590/S010040422010000500003

Lebranc, B. W., Davis, O. K., Boue, S., Delucca, A., \& Deeby, T. (2009). Antioxidant activity of Sonoran Desert bee pollen. Food Chemistry, 115, 1299-1305. http://dx.doi.org/10.1016/j.foodchem.2009.01.055

Liberato, M. C. T. C., Morais, S. M., Siqueira, S. M. C., Menezes, J, E. S. A., Ramos, D. N., Machado, L. K. A., \& Magalhães, I. L. (2011). Phenolic Content and Antioxidant and Antiacetylcholinesterase Properties of Honeys from Different Floral Origins. Journal of Medicinal Food, 14, 658-663. PMid:21554131. http://dx.doi. org/10.1089/jmf.2010.0097

Meda, A., Lamien, C. E., Romito, M., Millogo, J., \& Nacoulma, O. G. (2005). Determination of the total phenolic, flavonoid and proline contents in Burkina Fasan honey, as well as their radical scavenging activity. Food Chemistry, 91, 571-577. http://dx.doi.org/10.1016/j. foodchem.2004.10.006

Mesor, L. L., Menezes, F. S., Leitão, G. G., Reis, A. S., Santos, T. C., Coube, C. S., \& Leitão, S. G. (2001). Screening of Brazilian plant extracts for antioxidant activity by the use of DPPH free radical method. Phytotherapy Research, 15, 127-130. PMid:11268111. http:// dx.doi.org/10.1002/ptr.687

Orsolić, N., Benković, V., Horvat-Knezević, A., Kopjar, N., Kosalec, I., Bakmaz, M., Mihaljević, Z., Bendelja, K., \& Basić, I. (2007). Assessment by survival analysis of the radioprotective properties of propolis and its polyphenolic compounds. Biological \& Pharmaceutical Bulletin, 30(5), 946-951. http://dx.doi.org/10.1248/ bpb.30.946

Popova, M. P., Bankova, V. S., Bogdanov, S., Tsvetkova, I., Naydenski, C., Marcazzan, G. L., \& Sabatini, A. G. (2007). Chemical characteristics of poplar type propolis of different geographic origin. Apidologie, 38, 306-311. http://dx.doi.org/10.1051/apido:2007013

Popova, M., Bankova, V., Butovska, D., Petkov, V., Damyanova, B. N., Sabatini, A. G., Marcazzan, G. L., \& Bogdanov, S. (2004) Validated methods for the quantification of biologically active constituents of poplar-type propolis. Phytochemical Analysis, 15, 235-240. PMid:15311843. http://dx.doi.org/10.1002/pca.777

Popova, M., Silici, S., Kaftanoglu, O., \& Bankova, V. (2005). Antibacterial activity of Turkish própolis and its qualitative and quantitative chemical composition. Phytomedicine, 12, 221-228. PMid:15830845. http://dx.doi.org/10.1016/j.phymed.2003.09.007

Socha, R., Juszczak, L., Pietrzyk, S., \& Fortuna, T. (2009). Antioxidant activity and phenolic composition of herbhoneys. Food Chemistry, 113, 568-574. http://dx.doi.org/10.1016/j.foodchem.2008.08.029

Tylkowski, B., Trusheva, B., Bankova, V., Giamberini, M., Peev, G., \& Nikolova, A. (2010). Extraction of biologically active compounds from propolis and concentration of extract by nanofiltration. Journal of Membrane Science, 348, 124-130. http://dx.doi.org/10.1016/j. memsci.2009.10.049 